Article

\title{
Double Palindrome Water Chain in Cu(II) Theophylline Complex. Synthesis, Characterization, Biological Activity of Cu(II), Zn(II) Complexes with Theophylline
}

\author{
Michał Gacki ${ }^{1, *(D)}$, Karolina Kafarska ${ }^{1}$, Anna Pietrzak ${ }^{1}\left(\mathbb{D}\right.$, Izabela Korona-Głowniak ${ }^{2}(\mathbb{D})$ and \\ Wojciech M. Wolf ${ }^{1}$ \\ 1 Institute of General and Ecological Chemistry, Faculty of Chemistry, Lodz University of Technology, \\ 116 Zeromskiego Street, 90-924 Lodz, Poland; karolina.kafarska@p.lodz.pl (K.K.); \\ anna.pietrzak.1@p.lodz.pl (A.P.); wojciech.wolf@p.lodz.pl (W.M.W.) \\ 2 Department of Pharmaceutical Microbiology, Medical University of Lublin, Chodzki 1, 20-093 Lublin, \\ Poland; iza.glowniak@umlub.pl \\ * Correspondence: michal.gacki@edu.p.lodz.pl
}

Received: 22 January 2020; Accepted: 5 February 2020; Published: 8 February 2020

\begin{abstract}
Two metal complexes of theophylline were synthesized. Namely, 1 with the formula $\left.[\mathrm{Cu} \text { (theop) })_{2}\left(\mathrm{H}_{2} \mathrm{O}\right)_{3}\right] \cdot 2 \mathrm{H}_{2} \mathrm{O}$ and $\left.2,[\mathrm{Zn} \text { (theop) })_{2}\right] \cdot \mathrm{H}_{2} \mathrm{O}$ (where: theop = theophylline ion). Their properties were thoroughly investigated by the elemental analysis (EA), flame atomic absorption spectrometry (FAAS), Fourier-transform infrared spectroscopy (FTIR), and thermogravimetric analysis (TGA) that were augmented by antimicrobial and antioxidant analyses. Their radical scavenging ability (RSA) is notably higher than that of a pure theophylline itself. Similarly to theophylline complexes already studied by us 3, $\left.[\mathrm{Mn} \text { (theop })_{2}\left(\mathrm{H}_{2} \mathrm{O}\right)_{4}\right]$, $\left.[\mathrm{Co} \text { (theop) })_{2}\left(\mathrm{H}_{2} \mathrm{O}\right)_{4}\right]$ and 5, [Ni(theop $\left.)_{2}\left(\mathrm{H}_{2} \mathrm{O}\right)_{4}\right]$ title compounds are inactive against Gram-negative bacteria, but they show moderate or mild activity against Gram-positive rods. The low temperature, single crystal X-ray diffraction technique determines the crystal structure of $\mathbf{1}$. Its supramolecular crystal topology is affected by the unique, double palindrome water chain that formed by two conserved and a sole coordinated water molecules. Crystal packing arrangements were characterized by fingerprint plots that were derived from the Hirshfeld surfaces (HS), as calculated for all structures in the series 1, 3, 4, 5 .
\end{abstract}

Keywords: coordination complex; theophylline-complex; crystal structure; Hirshfeld surface analysis; palindrome water chain; antioxidant activity

\section{Introduction}

Xanthine alkaloids are among pharmacological agents extensively used worldwide [1]. They naturally occur in cacao beans and popular beverages, like tea or coffee [2-4]. The most popular and widely used xanthines are caffeine, theophylline, and theobromine [5], which highly appreciated for their medical activity [6-10]. Theophylline is an important methyloxantine (Scheme 1), initially extracted from tea leaves in 1888 by Albrecht Kossel [11]. Its chemical structure and first synthetic method was hammered out by Emil Fischer in 1895 [12]. At the beginning of the 20th century, theophylline was introduced into the pharmaceutical market. Initially, it found application as a diuretic [13], and was further used in the treatment of either asthma or chronic obstructive pulmonary disease $[14,15]$. The pharmacological action of theophylline follows its ability to relax smooth muscle (bronchi and pulmonary blood vessels) and modulate breathing activity. It also stimulates the myocardium and the central nervous system and decreases peripheral and venous 
pressure $[16,17]$. Nevertheless, the bronchodilator activity is essentially due to the (nonspecific) inhibition of adenosine and phosphodiesterase receptors [2,13].

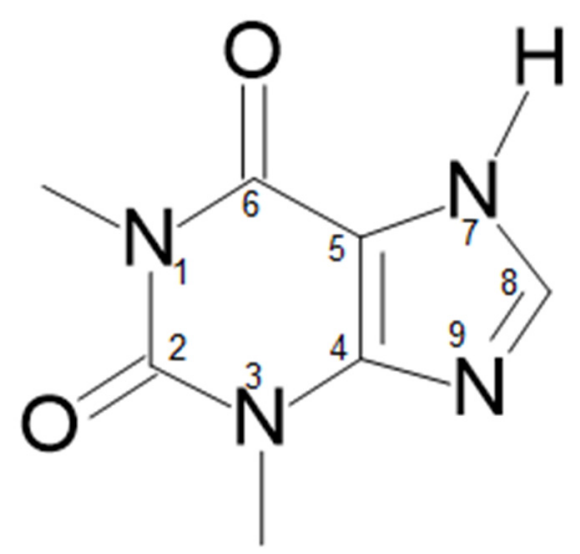

Scheme 1. Structural scheme of theophylline.

Theophylline (1,3-dimethyl-3,7-dihydro-1H-purin-2,6-dion), like all purines, is characterized by fused pyrimidine and imidazole rings [18]. The latter two endocyclic nitrogen atoms are either acidic or basic (N-7 and N-9, respectively) [19]. In water, theophylline behaves like a weak acid [19], with limited solubility $\left(0.55-0.8 \mathrm{~g} / 100 \mathrm{~mL}\left(25^{\circ} \mathrm{C}\right)\right)[20,21]$. It can be enhanced upon the transformation to salts through the reaction with organic bases. The resulting theophylline anion with ionized imidazole ring is stabilized by the combined mesomeric and inductive effects [22].

While metals and their salts have been extensively used in medicine for years [23], the modern metallodrugs are emerging new pharmaceuticals with very prospective new applications $[23,24]$. Metal binding changes drug properties, like redox potential, solubility, half-life time, and bio-catalytic ability, and finally may lead to the enhanced structural diversity and biological activity [25-27].

In particular, transition metal complexes with drugs have been attracting continuously growing interest [27]. Regrettably, only a limited number of complexes with theophylline have been reported so far [28-36]. In most cases, the coordinating atom is N7, while structures that involve N9 and O6 are also described $[32,35,36]$.

This work enhances our recent structural and biological studies on metal complexes with theophylline 3-5 (Scheme 2), which have been already published by us [28]. Here, we report synthesis, Fourier-transform infrared spectroscopy (FTIR) spectroscopy, thermal analysis, and antioxidant and antimicrobial activities of compounds 1-2. Additionally, the high quality, low temperature crystal structure of 1 was determined and then compared to the previously reported X-ray analysis, as published in 1994 by Begum and Manohar [30]. The latter structure was determined from X-ray intensities that were collected for a major component of the twinned crystal without resolving the twin law. That led to elimination of significant number of reflections from the final data set and resulted in a low precision of geometry parameters. Especially, $\mathrm{H}$ atoms were not identified on Fourier maps. Therefore, we have decided to redetermine the structure of $\mathbf{1}$ by a single-crystal X-ray analysis. In contrast to the former results, the high quality data were collected at low temperature $(\mathrm{T}=100 \mathrm{~K})$ and the final refinement yielded precise atomic coordinates. Moreover, peaks that were observed on the residual Fourier map defined all $\mathrm{H}$ atoms, including those disordered of water molecules. The latter were crucial for the identification and characterization of $\mathrm{H}$-bonded infinite chains, which are important supramolecular topology. 
<smiles>CCOC(O)(O)n1cnc2c1c(=O)n(C)c(=O)n2C(O)(O)O</smiles>

1

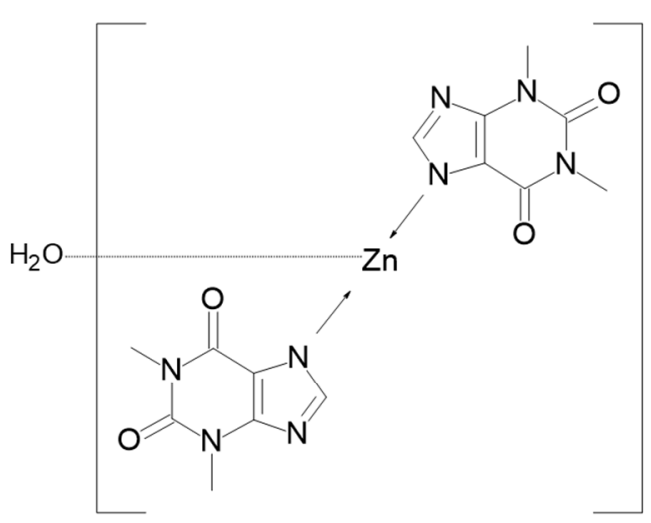

2

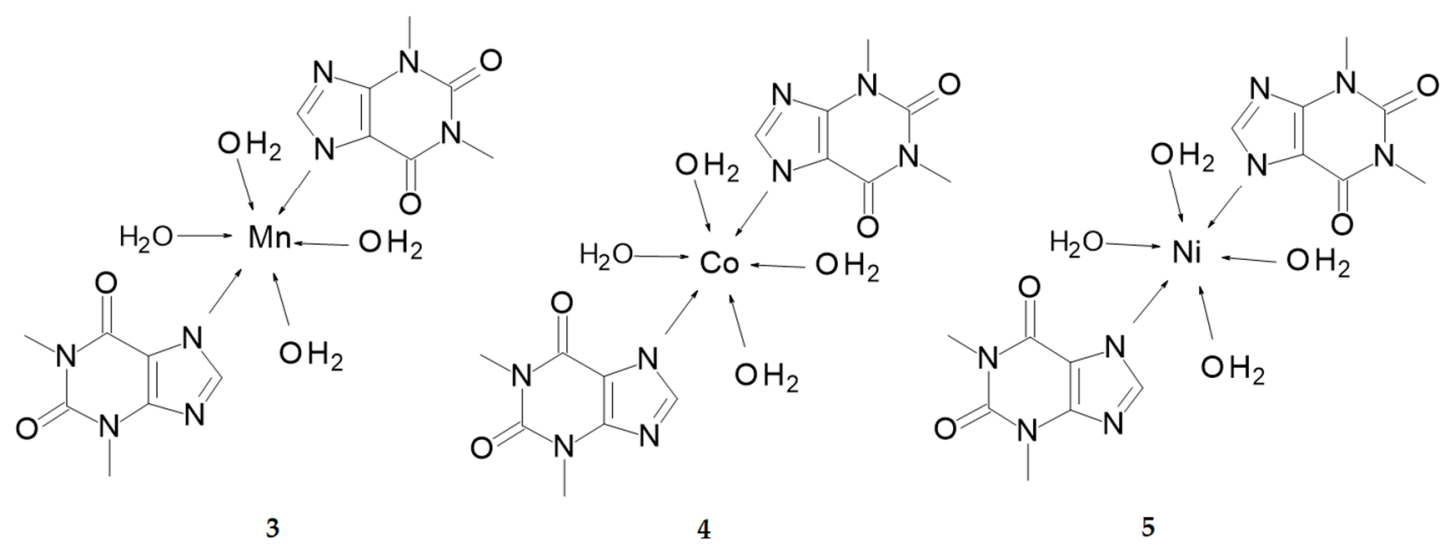

Scheme 2. Structural schemes of 1-5.

\section{Experimental}

\subsection{Preparation of Complexes and Crystallization}

Compounds 1, 2 were synthesized following procedure, as described by us in [28]. Single crystals of one suitable for X-ray structure analysis were obtained at room temperature by slow evaporation from the aqueous/ethanol (1:2 v/v) solution. Good quality crystals appeared after two weeks. Numerous attempts to obtain single crystals of two were unsuccessful. Anal. calcd. for $1 \mathrm{C}_{14} \mathrm{H}_{24} \mathrm{CuN}_{8} \mathrm{O}_{9}(\%)$ : $\mathrm{C}$, $32.84 \mathrm{H}, 4.73 ; \mathrm{N}, 21.89 ; \mathrm{Cu}, 12.41$. Found: C, 32.09; H. 5.12; N, 21.55; Cu, 12.45, and for $2 \mathrm{C}_{14} \mathrm{H}_{16} \mathrm{ZnN}_{8} \mathrm{O}_{5}$ (\%): C, 38.07; H, 3.65; N, 25.37; Zn, 14.80. Found: C, 38.12; H. 3.55; N, 25.13; Zn, 14.67.

\subsection{Materials and Methods}

Theophylline was purchased from Sigma-Aldrich and then used without further purification. Metal acetates $\mathrm{M}\left(\mathrm{CH}_{3} \mathrm{COO}\right)_{2} \cdot \mathrm{nH}_{2} \mathrm{O}$ (where $\mathrm{M}=\mathrm{Cu}, \mathrm{Zn}$ ), methanol, and (2,2- diphenyl-1-picrylhydrazyl) DPPH free radical were purchased from Lab-Scan, other chemicals were from POCh- Gliwice, Poland. All of the reagents were chemically pure.

Elemental analysis (EA) and flame atomic absorption spectrometry determined the chemical composition of $\mathbf{1}$ and $\mathbf{2}$. The metal content was determined in (20 $\mathrm{mg})$ samples that were initially mineralized by the Multiwave 3000 (Anton Paar GmbH, Graz, Austria) closed microwave system; the mixture of concentrated $\mathrm{HNO}_{3}$ and $\mathrm{HCl}(6: 1, v / v)$ was applied. The metal concentrations were measured by the flame atomic absorption spectrometry (FAAS) with the GBC Scientific Equipment 932 plus spectrometer (GBC Scientific Equipment, Braeside, Australia). The hydrogen, carbon, and nitrogen contents were measured with the Vario EL III Elemental Analyzer (Elementar Analysensysteme GmbH, Langenselold, Germany). 
The infrared spectra of theophylline, $\mathbf{1}$ and $\mathbf{2}$ were recorded with the Thermo Scientific Nicolet 6700 FTIR spectrometer (Thermo Scientific, Waltham, USA) that was equipped with liquid nitrogen cooled MCT (Mercury cadmium telluride- $\mathrm{MCT}, \mathrm{HgCdTe}$ ) detector. The samples were prepared as $\mathrm{KBr}$ pellets and measured over the range $4000-400 \mathrm{~cm}^{-1}$.

The thermal decomposition and stability of complexes were studied by thermogravimetric techniques. All of the measurements were made with the Netzsch TG 209 apparatus (Netzsch, Germany). The samples (10 mg) were heated (in ceramic crucibles) up to $1000{ }^{\circ} \mathrm{C}$, at a heating rate $10^{\circ} \mathrm{C} \mathrm{min}^{-1}$ in the air atmosphere.

The radical scavenging activity of 1, 2 and pure theophylline were evaluated by measuring scavenging ability of the DPPH free radical. The methodology that was suggested by Feng et al. [37] was used.

X-ray data were collected at $100 \mathrm{~K}$ on the XtaLAB Synergy, Dualflex, Pilatus $300 \mathrm{~K}$ diffractometer (Rigaku Corporation, Tokyo, Japan) that was equipped with the PhotonJet microfocus X-ray tube. Data reduction was performed with the CrysAlisPro [38]. The structure was solved by Intrinsic Phasing as in ShelXT [39] and further refined on $F^{2}$ in Olex2 [40] and ShelXL [41] by full-matrix least squares. The non-hydrogen atoms were anisotropically refined. Positions of disordered hydrogen atoms were identified on the difference Fourier maps. Their geometry was constrained while using DFIX and DANG commands, while the occupancy ratios were determined by the refinement of respective free variables. The remaining hydrogen atoms were initially located on difference Fourier maps, being further restrained to their geometrical positions and refined riding on their parent atoms. The molecular plots and packing diagrams were drawn while using Mercury [42]. Geometry parameters were computed with PLATON [43]. Table 1 provides the relevant crystallographic data.

Table 1. Crystal data and structure refinement parameters for $\mathbf{1}$.

\begin{tabular}{cc}
\hline & $\mathbf{1}$ \\
\hline Empirical formula & $\mathrm{C}_{14} \mathrm{H}_{24} \mathrm{CuN}_{8} \mathrm{O}_{9}$ \\
Formula weight & 511.95 \\
$\mathrm{~T}(\mathrm{~K})$ & 100.0 \\
Crystal system & Monoclinic \\
Space group & $P 2_{1} / n$ \\
$\mathrm{a}(\AA)$ & $12.3749(2)$ \\
$\mathrm{b}(\AA)$ & $11.9281(3)$ \\
$\mathrm{c}(\AA)$ & $13.7162(2)$ \\
$\alpha\left(^{\circ}\right)$ & 90 \\
$\beta\left(^{\circ}\right)$ & $98.133(10)$ \\
$\gamma\left({ }^{\circ}\right)$ & 90 \\
$V\left(\AA^{3}\right)$ & $2004.27(7)$ \\
$\mathrm{Z}$ & 4 \\
$\rho_{\text {calc }}\left(\mathrm{g} / \mathrm{cm}^{3}\right)$ & 1.697 \\
$\mathrm{~F}(000)$ & 1060 \\
Radiation & $\mathrm{CuK} \alpha(\lambda=1.54184)$ \\
$\theta$ range $\left({ }^{\circ}\right)$ & $4.506-70.052$ \\
Reflections collected & 43730 \\
Independent reflections & 3811 \\
Goodness-of-fit $(\mathrm{GOF})$ & 1.061 \\
$\mathrm{R}[\mathrm{I}>=2 \sigma(\mathrm{I})]$ & 0.0295 \\
$w \mathrm{R}_{2}[\mathrm{I}>=2 \sigma(\mathrm{I})]$ & 0.0810 \\
\hline &
\end{tabular}

The CIF file for $\mathbf{1}$ is available from the Cambridge Crystallographic Data Centre (CCDC) (deposition numbers CCDC: 1973265). CCDC 1973265 contains supplementary crystallographic data for $\mathbf{1}$. These data can be obtained free of charge via http://www.ccdc.cam.ac.uk/conts/retrieving.html, or from the Cambridge Crystallographic Data Centre, 12 Union Road, Cambridge CB2 1EZ, UK; fax: $(+44)$ 1223-336-033; or e-mail: deposit@ccdc.cam.ac.uk. Hirshfeld Surfaces were generated while using 
the CrystalExplorer17 program (University of Western Australia, Crawley, Australia). Molecular geometries were taken directly from the crystal structure. For molecular fragments where the crystallographic disorder was identified, the major components were only considered. The distances from the HS to the nearest atom interior and exterior to the surface $\left(d_{\mathrm{i}}\right.$ and $d_{\mathrm{e}}$, respectively) were calculated and plotted as scattergrams [44]. A quantitative decomposition analysis of atom-to-surface contacts was calculated as a percentage of the points in the Hirshfeld Surface, with $d_{\mathrm{i}}$ and $d_{\mathrm{e}}$ for specific atom pairs.

Theophylline derivatives were screened for antibacterial and antifungal activities by methods already described by us in [45].

\section{Results and Discussion}

Compounds 1 and 2 are air stable at room temperature. They are moderately soluble in water, while being well soluble in popular polar organic solvents (e.g. DMF, DMSO, methanol, and ethanol). Their properties were thoroughly investigated by the FAAS, EA, FTIR, and thermogravimetric analysis augmented by antimicrobial and antioxidant analyses. Additionally, structure of $\mathbf{1}$ was determined by the single crystal X-ray diffraction technique.

\subsection{Crystal Structure}

Figure 1 presents the molecular structure of complex 1 . It crystallizes in the monoclinic space group $P 2_{1} / n$. The asymmetric unit contains a single copper cation, two independent theophylline anions, and three directly coordinated waters augmented by two additional, conserved water molecules in the outer coordination sphere. The central copper ion adopts distorted square pyramidal coordination. It is surrounded by two almost planar, imidazole N6 and N7 atoms that were supplemented with two axial O5, O6, and a sole apical O7 water molecules. The latter coordination bond, Cu-O7 is longer [2.2628(13)

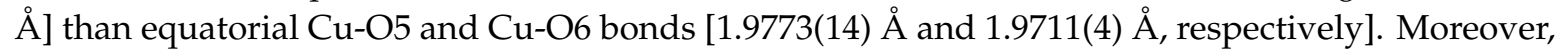
angles that formed by $\mathrm{O} 7$ with equatorial atoms are within the range $91.06-102.85^{\circ}$. The central $\mathrm{Cu}$ ion is located $0.183 \AA$ above the square pyramid base plane with theophylline moieties positioned trans and the N5-Cu-N6 angle close to a half-turn angle [161.17(6) $\left.{ }^{\circ}\right]$. On the contrary, complexes 3-5 are characterized by octahedral geometry with coordinating water molecules in equatorial positions and nitrogen atoms placed axially. The Cu-N5 and Cu-N6 bond distances are shorter [1.9814(15) $\AA$, 1.9888(15) $\AA$ ], then Mn-N7, Co-N7, and Ni-N7 [2.2690(11) $\AA$, 2.1890(13) $\AA$ and 2.1310(3) $\AA$ ] for 3, 4, and 5, respectively. Furthermore, metal-O distances in equatorial positions are longer for 3, 4, and 5 than those in $\mathbf{1}$.

The crystal structure $\mathbf{1}$ is stabilized by an extensive network of inter- and intramolecular hydrogen bonds (Table 2). In particular, the strong intramolecular interaction is formed between a sole hydrogen at the coordinating water molecule $\mathrm{O} 7$ and the carbonyl $\mathrm{O} 1$ of a theophylline moiety. Conserved waters $\mathrm{O} 8$ and $\mathrm{O} 9$ along with the coordinating water $\mathrm{O} 7$ form 1-D, double palindrome chains running along the [100] direction. Those species may be described by the symbol $C_{4}^{4}(9)$, according to Etter and Bernstein terminology [46]. They are restricted by two inversion centres located at midpoints of the O7 . O $[1-x, 1-y, 1-z]$ and O9... O9 [1-x, 1-y, -z] intra-chain H-bonds, as in Figure 2. Those constraints heavily affect the hydrogen bond geometry and the inflict disorder of hydrogen atoms in those symmetry driven species. Moreover, the coordinating water molecules O5 and O6 are involved in hydrogen-bonding interaction with the carboxyl O2 and O3 groups and imidazole N3 and N7 atoms, respectively. Those interactions form the supramolecular puckered ribbons, which run along the [010] direction (Figure 3). The crystal packing is additionally stabilized by the $\pi \cdots \pi$ interaction between purine moieties of the neighboring residues, and an average separation is $3.480(5) \AA$. 


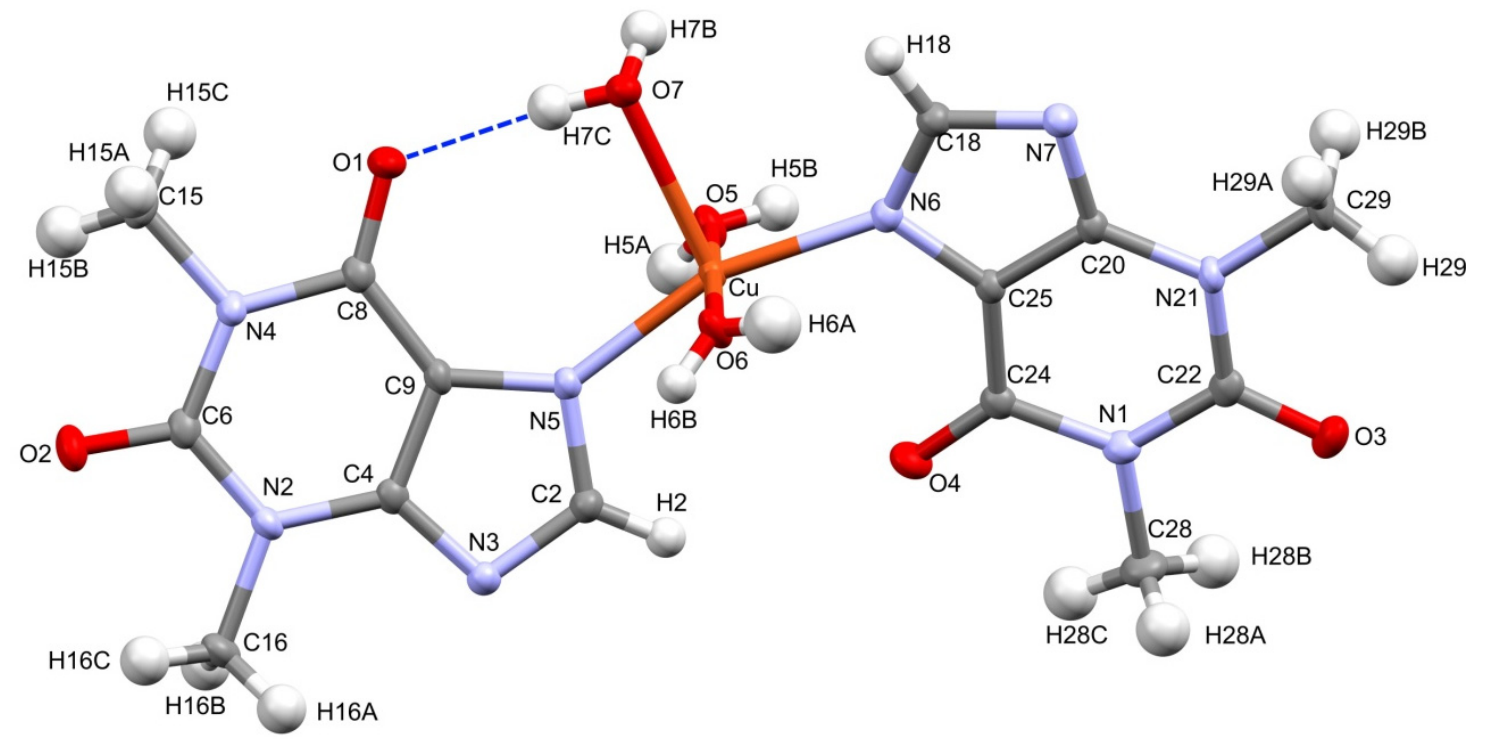

Figure 1. Molecular structure of 1. Conserved waters O8 and O9 are omitted for clarity. Displacement ellipsoids are drawn at the $50 \%$ probability level. Hydrogen atoms are represented by spheres of an arbitrary radius. Intramolecular hydrogen bond is shown with a broken line in blue.

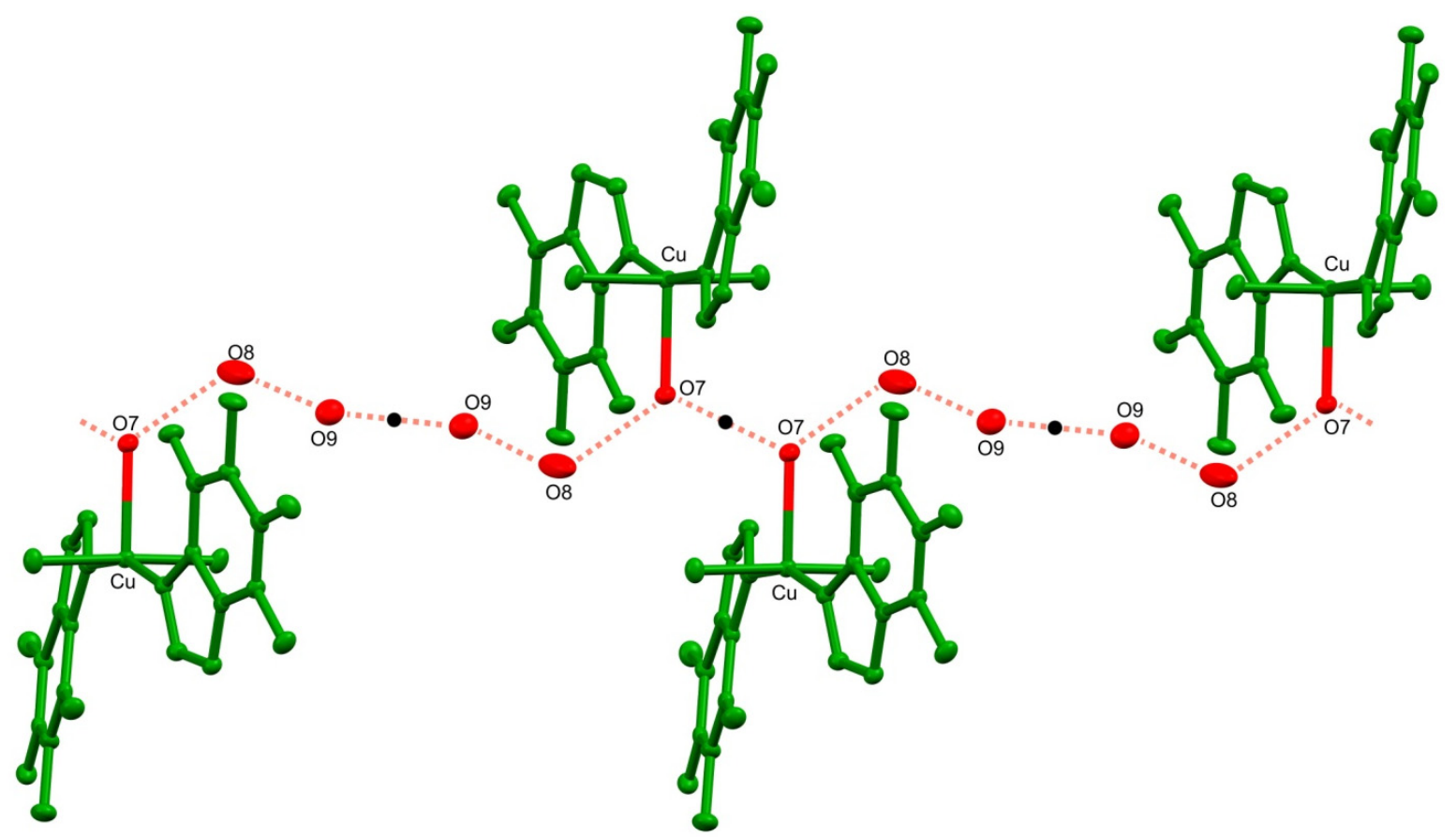

Figure 2. Fragment of the double palindrome water chain in 1 running along the [100] direction. Symmetry centers are indicated with black dots. Hydrogens atom are omitted for clarity. 
Table 2. Hydrogen bond geometry in $\mathbf{1}\left({ }^{\circ}, \AA\right)$. H7A, H8A, and H9A atoms are disordered over two sites, their secondary positions are labeled H7B, H8B, and H9B, respectively. All of those sites participate in hydrogen bonding.

\begin{tabular}{|c|c|c|c|c|}
\hline D-H $\cdots A$ & D-H & $\mathbf{H} \cdots \mathbf{A}$ & $\mathbf{D} \cdots \mathbf{A}$ & D-H $\cdots A$ \\
\hline $\mathrm{O} 5-\mathrm{H} 5 \mathrm{~A} \cdots \mathrm{O} 2^{\mathrm{a}}$ & $0.77(3)$ & $1.94(3)$ & $2.701(2)$ & $175(3)$ \\
\hline O5-H5B $\cdots \mathrm{O}^{\mathrm{b}}$ & $0.81(2)$ & $1.94(3)$ & $2.722(2)$ & $162(2)$ \\
\hline O6-H6A $\cdots$ N3 ${ }^{c}$ & $0.73(3)$ & $2.00(3)$ & $2.721(2)$ & $174(3)$ \\
\hline O6-H6B $\cdots$ N7 $^{d}$ & $0.77(2)$ & $1.99(2)$ & $2.756(2)$ & 179(3) \\
\hline O7-H7A $\cdots \mathrm{O} 8$ & $0.80(4)$ & $1.95(4)$ & $2.748(2)$ & $170(5)$ \\
\hline O7-H7B $\cdots \mathrm{O}^{\mathrm{e}}$ & $0.81(4)$ & $1.94(4)$ & $2.749(2)$ & $175(5)$ \\
\hline O7-H7C $\cdots$ O1 & $0.82(2)$ & $1.87(2)$ & $2.686(2)$ & $172(2)$ \\
\hline O8-H8A $\cdots 3^{f}$ & $0.82(3)$ & $2.14(3)$ & $2.956(2)$ & $173(5)$ \\
\hline O8-H8B $\cdots$ O9 & $0.83(2)$ & $1.89(4)$ & $2.712(3)$ & $170(2)$ \\
\hline O8-H8C $\cdots$ O7 & $0.78(4)$ & $2.20(4)$ & $2.748(2)$ & $127(4)$ \\
\hline O9-H9A $\cdots$ O8 & $0.80(3)$ & $1.92(3)$ & $2.712(3)$ & $169(3)$ \\
\hline O9-H9B $\cdots$ O9g & $0.81(2)$ & $1.94(5)$ & $2.753(2)$ & 177(7) \\
\hline O9-H9C $\cdots$ O4 & $0.80(2)$ & $2.07(2)$ & $2.849(2)$ & $163(3)$ \\
\hline
\end{tabular}

Symmetry codes: $\left({ }^{\mathrm{a}}\right)-\mathrm{x},-\mathrm{y}, 1-\mathrm{z} ;\left(^{\mathrm{b}}\right)-\mathrm{x}, 1-\mathrm{y}, 1-\mathrm{z} ;\left(^{\mathrm{c}}\right) \frac{1}{2}-\mathrm{x}, \frac{1}{2}+\mathrm{y}, \frac{1}{2}-\mathrm{z} ;\left(^{(\mathrm{d}}\right) \frac{1}{2}-\mathrm{x},-\frac{1}{2}+\mathrm{y}, \frac{1}{2}-\mathrm{z} ;\left(^{(\mathrm{e}}\right) 1-\mathrm{x}, 1-\mathrm{y}, 1-\mathrm{z} ;\left(^{\mathrm{f}}\right) 1+\mathrm{x}$, $\mathrm{y}, \mathrm{z} ;{ }^{(g)} 1-\mathrm{x}, 1-\mathrm{y},-\mathrm{z}$.

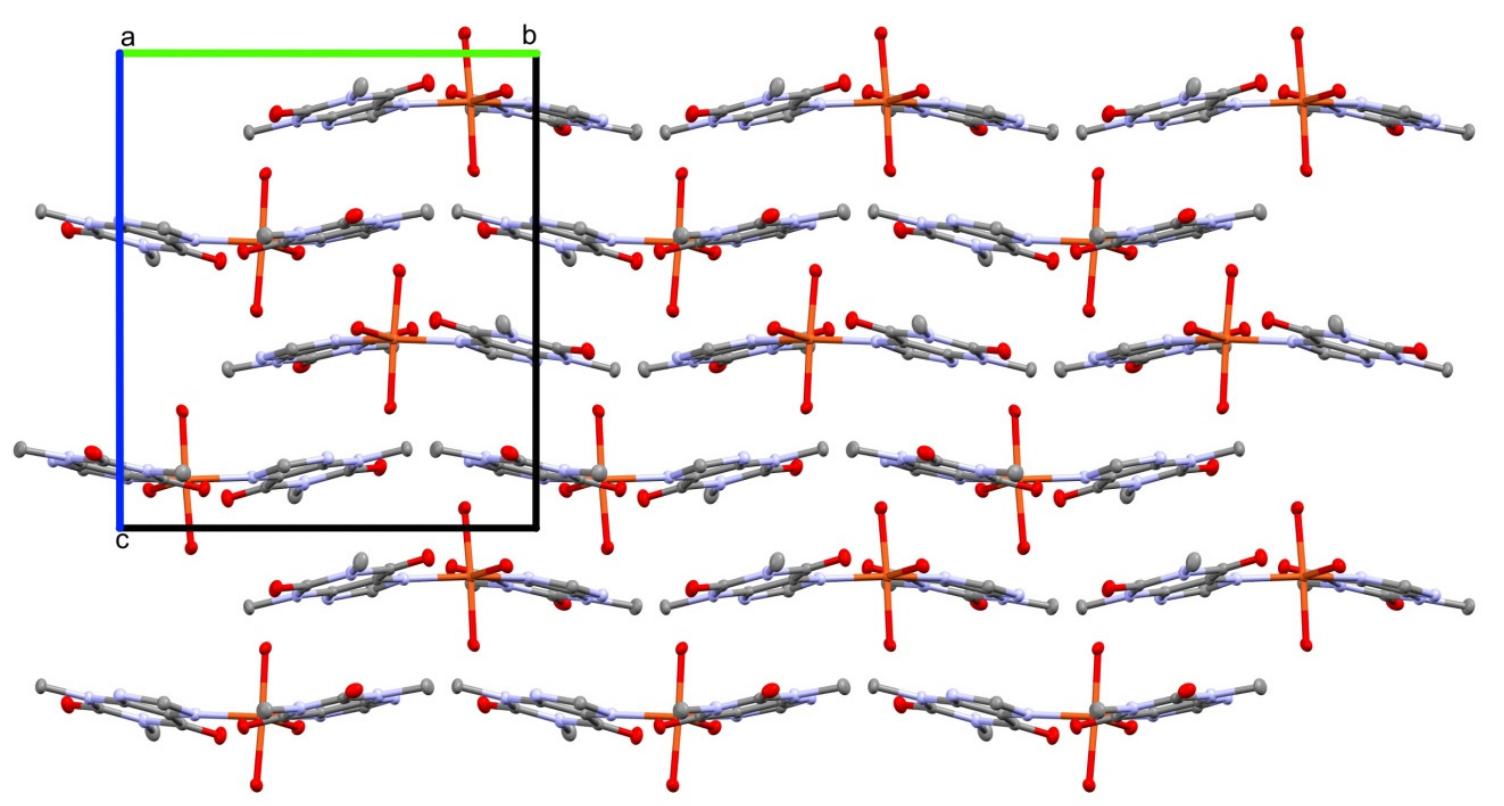

Figure 3. The supramolecular puckered ribbons running along the [010] direction. Crystals axes are indicated by a, b and c symbols.

Crystal Packing Analysis

Structures 1, 3, 4, and 5 exhibit similar molecular shapes, as represented by their Hirshfeld surfaces (HS), Figure 4. In 1, three water molecules are in the inner coordination sphere, while in 3-5, central metal ion coordinates four waters. The overall molecular shape is strongly influenced by two large, planar and rigid theophylline moieties. The crystal packing of $\mathbf{1}$ is additionally affected by two conserved water molecules $\mathrm{O} 8$ and $\mathrm{O} 9$, which are not directly linked to the copper cation. On the contrary, in 3-5, all waters are within the metal coordination sphere. 


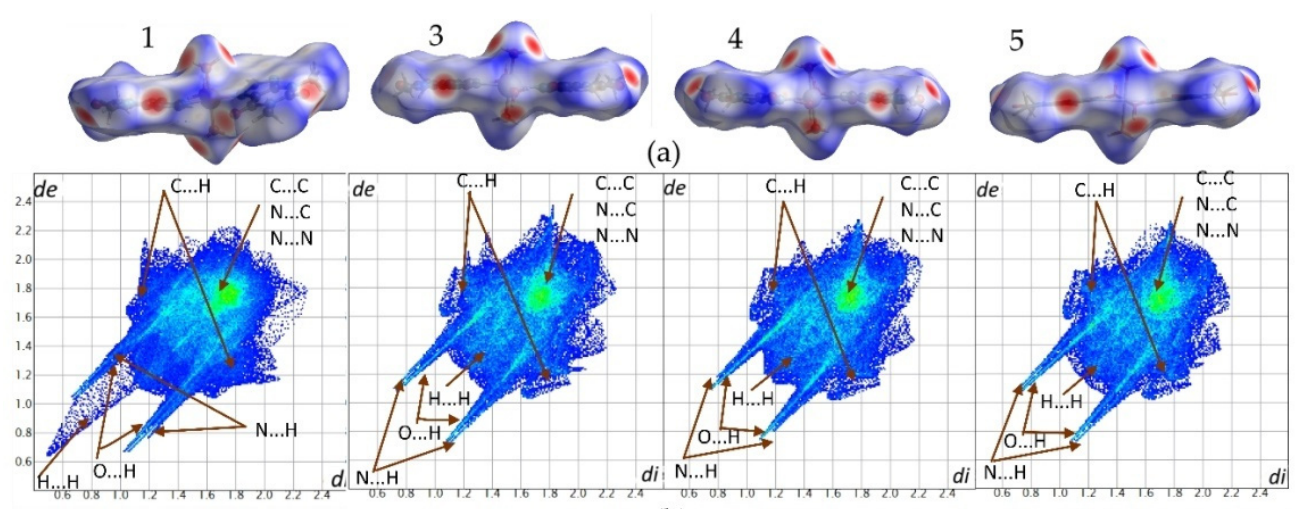

(b)

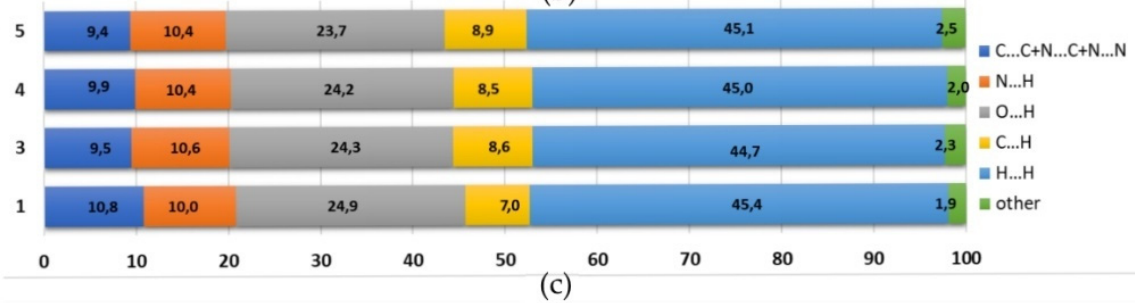

Figure 4. (a) Molecular shapes of $\mathbf{1}$ and 3-5 visualized as Hirshfeld surfaces; (b) Fingerprint plots generated for single molecules. Labels indicate regions of specific interatomic interactions; and, (c) The percentage contributions to the Hirshfeld surface areas for major intermolecular contacts.

The hydration of 1 drives changes in the supramolecular assembly as compared to 3-5. In particular, two conserved water molecules are linked by hydrogen bonds and encapsulated in tight pockets. As described above, these dimers are further connected with coordinated water molecules. The resulting double palindrome water chains are located in channels, as presented in Figure 5.

Fingerprint plots (FP) that were derived from the HS were generated for all analyzed structures to characterize used to the crystal packing arrangements in detail. The relevant FP and their percentage contributions to the HS area for the major intermolecular contacts do not differ significantly, as crystals 3-5 are isostructural. Additionally, the FP defining environment of the molecule in $\mathbf{1}$ reflects similarities in the overall intermolecular contacts contribution as compared to 3-5. Especially, in 1, two non coordinated water molecules are a source of additional hydrogen bonding. Nevertheless, no significant differences in $\mathrm{O} \cdots \mathrm{H}$ contacts contribution are observed i.e. $24.9 \%, 24.3 \%, 24.2 \%$, and $23.7 \%$ for 1, 3, 4, and 5, respectively. Sharp spikes representing those interactions on FP plots almost overlap with spikes that were derived from $\mathrm{N} \cdots \mathrm{H}$ contacts. The latter contribute in the crystal stabilization to a smaller extent, ranging in value from $10.0 \%$ to $10.6 \%$. Moreover, symmetrical wings that reflect $C \cdots \mathrm{H}$ contacts characterize all FP. Those indicate notable participation of $\mathrm{C}-\mathrm{H} \cdots \pi$ interactions between methyl group and aromatic, stacked theophylline moieties. Respective contributions of $\mathrm{C} \cdots \mathrm{H}$ contacts defining 3-5 range in value from $8.5 \%$ to $8.9 \%$, while in $\mathbf{1}$ the smaller contribution of $7.0 \%$ is observed. In all structures, molecules are assembled in stacks and consequent bright spots in the central region of FP are observed. This region is typical for $C \cdots C, C \cdots N$, and $N \cdots N$ contacts, which follow stacking interactions between aromatic fragments of molecules. Their contributions in $\mathbf{1}$ and $\mathbf{3} \mathbf{- 5}$ are notably smaller $(10.8 \%, 9.4 \%, 9.9 \%$, and $9.5 \%$, respectively) as compared to the sum of contacts defining typical donor-acceptor interactions $(\mathrm{C} \cdots \mathrm{H}, \mathrm{O} \cdots \mathrm{H}, \mathrm{N} \cdots \mathrm{H})$. The latter is higher than $40 \%$ in all of the investigated crystals. The $\mathrm{H} \cdots \mathrm{H}$ contacts dominate over all $\mathrm{FP}$, with their contribution ranging in value from $44.7 \%$ to $45.4 \%$ for 3 and 1 , respectively. The $\mathrm{H} \cdots \mathrm{H}$ contacts plotted on FP scattergrams of $\mathbf{1}$ are shorter than respective van der Waals radii due to the disorder of water hydrogen atoms. 


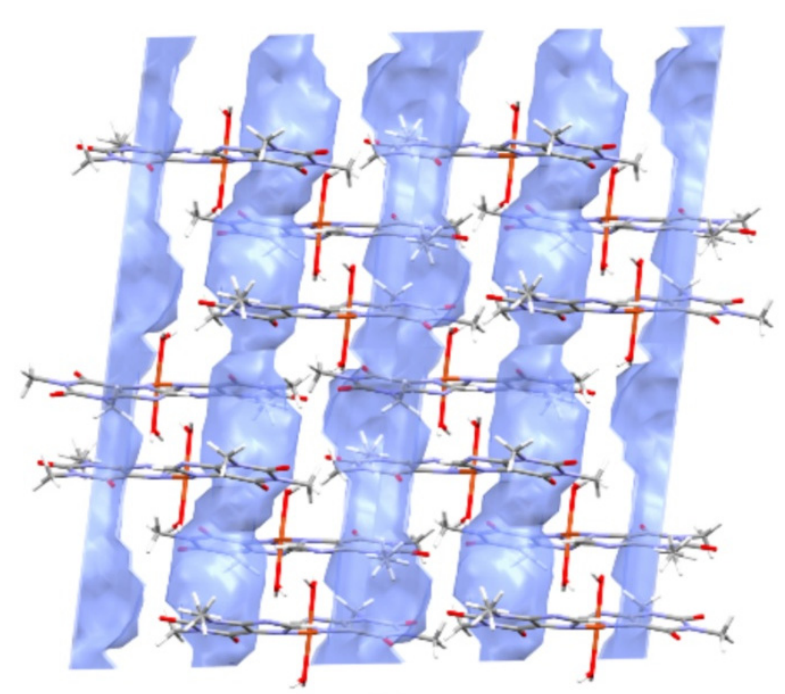

(a)
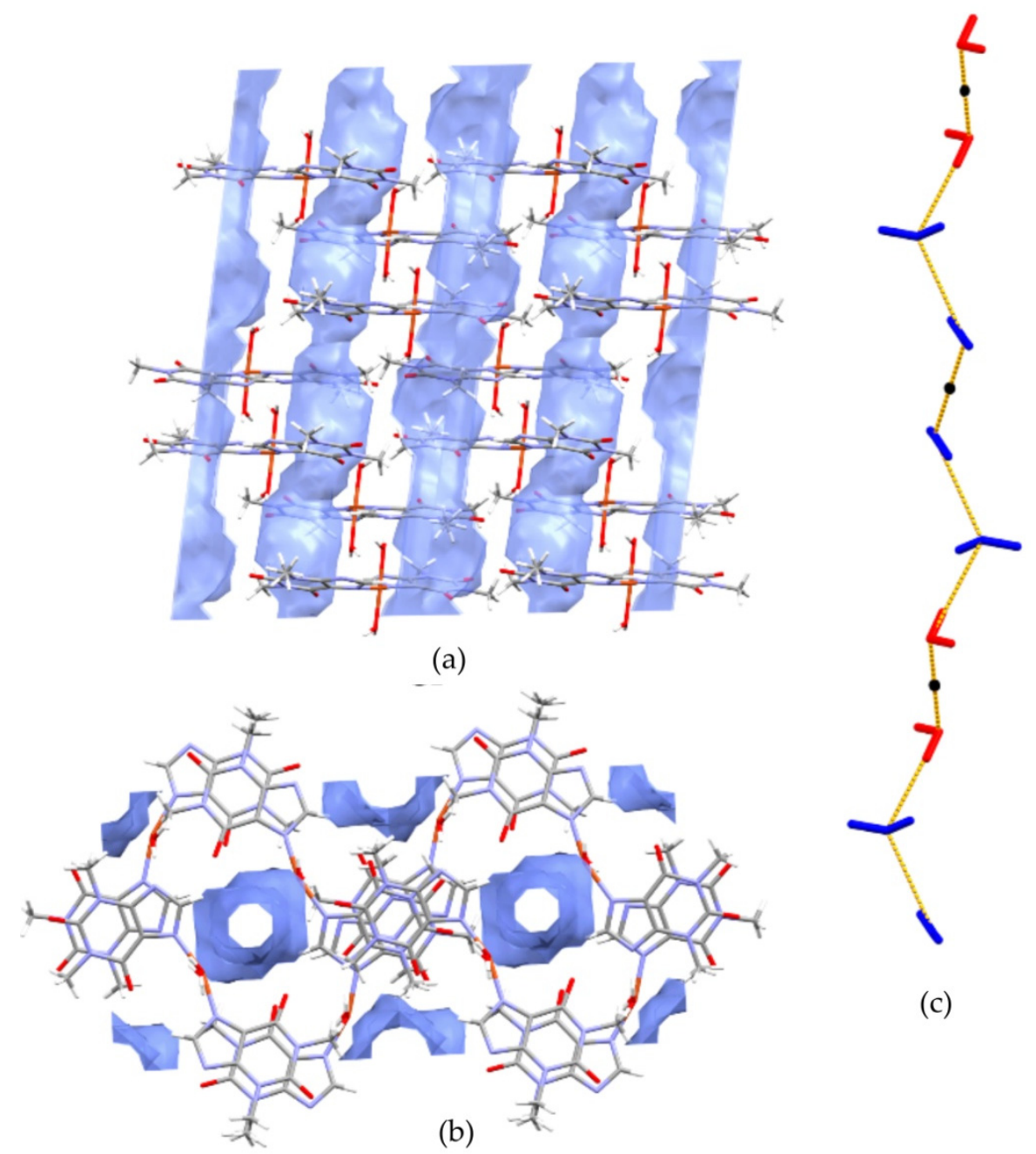

(c)

Figure 5. The channels occupied by water molecules in the crystal of $\mathbf{1}$ as drawn along the $b$ axis (a) and the $a$ axis (b). Void volumes are based on contact surface as calculated by Mercury, with a grid step of $0.7 \AA$ and a probe radius of $1.2 \AA$. Infinite chains propagated along [100] direction are constituted of non coordinated (blue) and coordinated (red) water molecules associated through hydrogen bonds (c).

Black dots indicate symmetry centres.

\subsection{Infrared Spectra}

The IR spectra of $\mathbf{1}$ and $\mathbf{2}$ are similar to those recorded for 3, 4, 5. All of the complexes exhibit sharp bands around the $3600 \mathrm{~cm}^{-1}$ augmented by a broad absorption bands in the region $3500-3200 \mathrm{~cm}^{-1}$. The former and latter are assigned to $\mathrm{OH}$ stretching vibrations in water molecules. The free theophylline shows a characteristic band at $3116.5 \mathrm{~cm}^{-1}$ that is associated with the $v(\mathrm{NH})$ vibration. As expected, this band disappears in the IR spectra of all complexes. It indicates the deprotonation of theophylline where the amine group interacts with metal ions. The characteristic stretching vibrations that are attributed to $C=O\left(1650-1720 \mathrm{~cm}^{-1}\right)$ and $C=C, C=N\left(1550-1670 \mathrm{~cm}^{-1}\right)$ of $^{-}$ the purine ring are shifted towards lower frequencies for all complexes. Those changes are affected by the theophylline coordination to metal ions and the subsequent formation of hydrogen bond network in the crystal. Figure 6 presents the comparison of IR spectra as in 1, 2 and a free theophylline. 


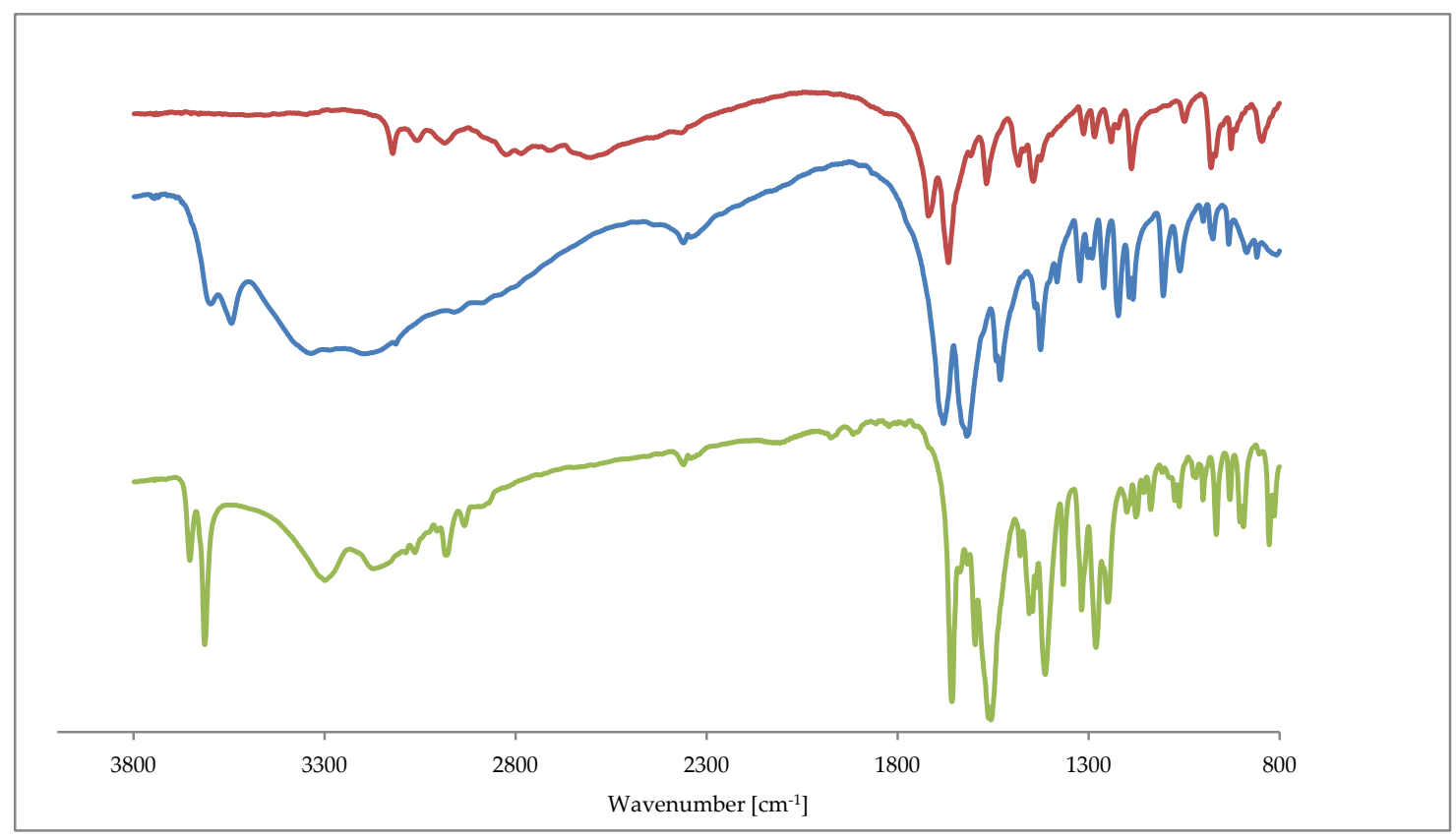

Figure 6. Fourier-transform infrared spectroscopy (FTIR) spectra of theophylline (red line), 1 (blue line) and 2 (green line).

\subsection{TG-DTG-DTA Measurements}

Figures 7 and 8 show the thermal decomposition curves of $\mathbf{1}$ and 2, respectively. All of the complexes start to decompose by a dehydration process. It corresponds to the endothermic effect on the DTA curve. The elimination of water molecules in $\mathbf{1}$ proceeds in three distinguished steps. The first is represented by a loss of two water molecules at the temperature range $50-95^{\circ} \mathrm{C}$ (mass loss exp. $6.51 \%$, calc. $7.04 \%$ ). The second is attributed to the release of one coordinated water with the weight loss $3.01 \%$ (teor. $3.52 \%$ ) at the temperature range of $95-125^{\circ} \mathrm{C}$. The loss of two remained, coordinated water molecule (mass loss exp. $6.51 \%$, calc. $7.04 \%$ ) leads to the formation of anhydrous $\mathrm{Cu}$ (theop) $)^{+}$complex at $200{ }^{\circ} \mathrm{C}$. Dehydration for 2 is a one stage process $\left(100-250{ }^{\circ} \mathrm{C}\right)$. Further heating leads to the destruction of theophyllinato ligands. The latter proceeds in two separate steps for $\mathbf{1}$ and one for 2. The corresponding exoeffects were identified on respective DTA curves. The experimental weight losses were $34.01 \%, 33.16 \%$ (calc. $35.00 \%$ ) and $76.71 \%$ (calc. $77.50 \%$ ) for $\mathbf{1}$ and 2, respectively. At temperatures above $500{ }^{\circ} \mathrm{C}$, the thermally stable metal oxides are being formed. They are the final product of thermal decomposition. The experimental residual masses for $\mathbf{1 ,} \mathbf{2}$ are close to the calculated ones, $\mathrm{CuO}$ : exp. $15.86 \%$, calc. $15.54 \%$; ZnO: exp. $18.31 \%$, calc. $18.42 \%$. 


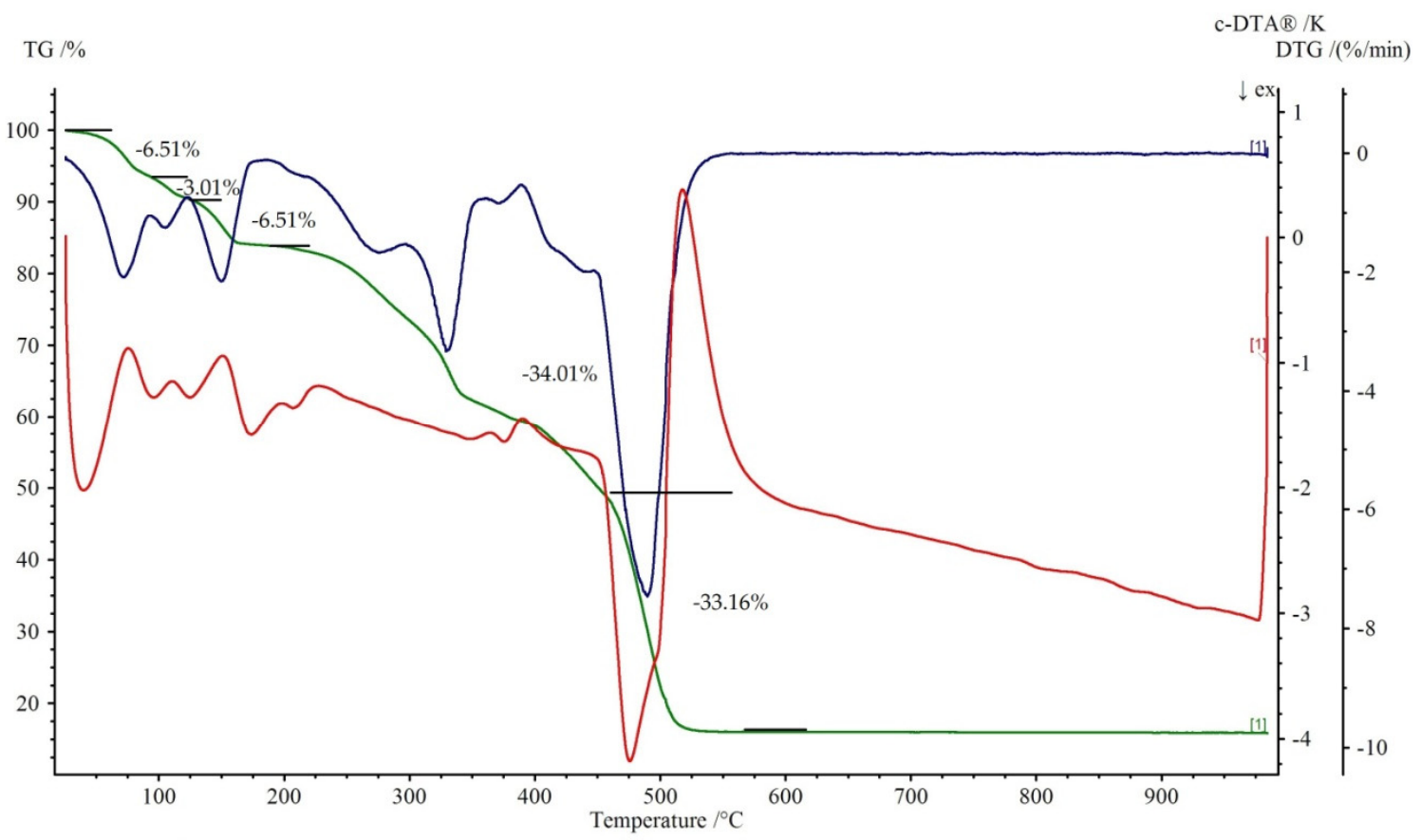

Figure 7. Thermoanalytical curves of $\mathbf{1}$. Thermogravimetric (TG) is in green with percentage weight losses, DTG is in blue while DTA is in red.

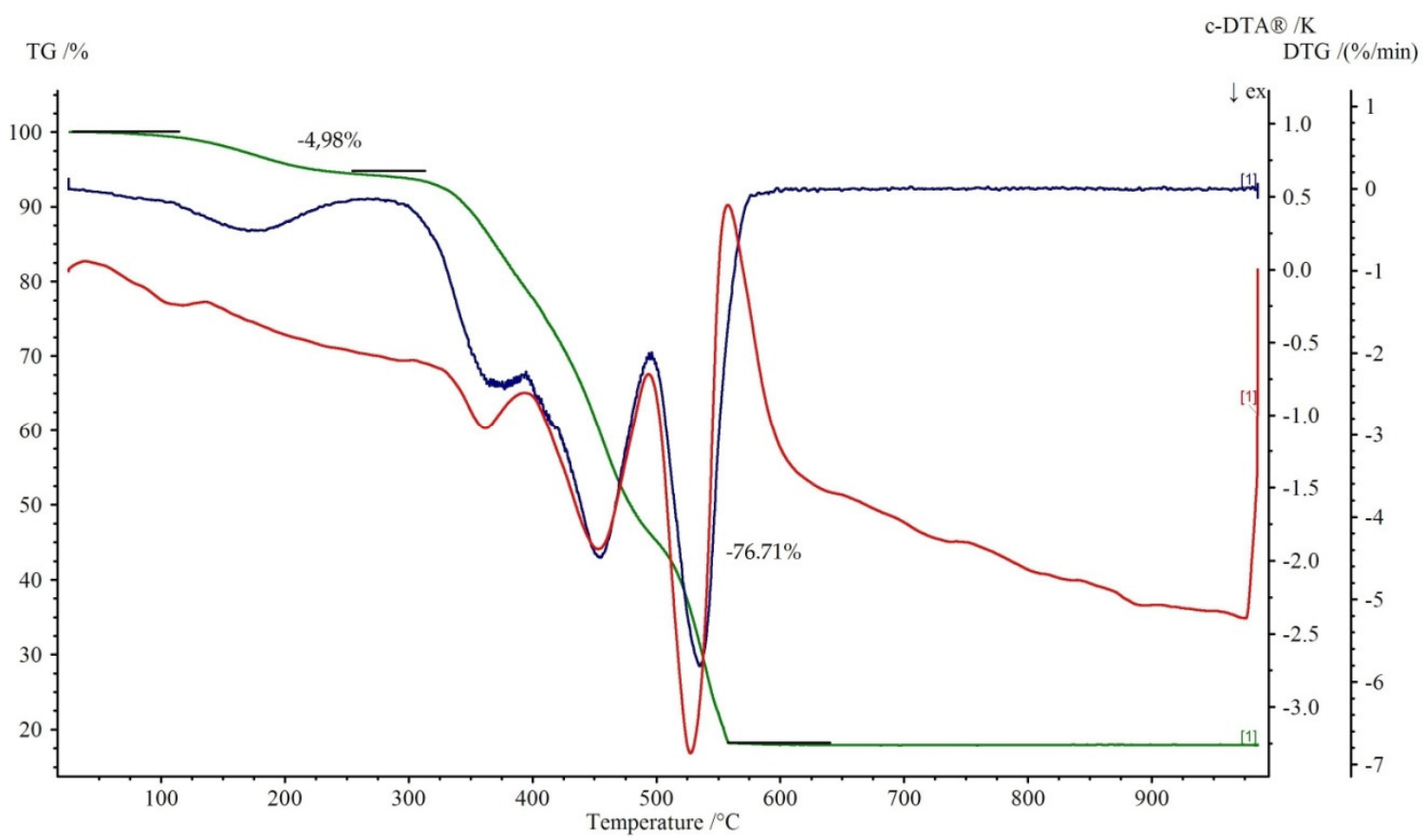

Figure 8. Thermoanalytical curves of 2. TG is in green with percentage weight losses, DTG is in blue while DTA is in red.

\subsection{Antioxidant and Antimicrobial Activities}

Figure 9 shows the radical scavenging activities for 1, 2 and a pure theophylline. The DPPH (2,2- diphenyl-1-picrylhydrazyl) scavenging activities of metal complexes are higher than that of a pure ligand. The maximum values for $0.1 \mathrm{~mol} / \mathrm{L}$ concentrations were $70.6 \%$ and $78.6 \%$ for $\mathbf{1}$ and $\mathbf{2}$, respectively. Moreover, the activity of 1, 2 and that of a pure theophylline have also been tested against reference strains of Gram-positive (S. aureus, S. epidermidis, M. luteus, E. faecalis, B. subtillis, B. cereus, S. 
pyogenes, S. pneumonia, and S. mutans), Gram-negative (S. typhimurium, E. coli, P. mirabilis, K. pneumonia, and P. aeruginosa), and bacteria and yeasts (C. albicans, C. parapsilosis, and C. glabrata). None of the tested compounds exhibit activity against Gram-negative rods (with MIC > $1000 \mathrm{mg} / \mathrm{L}$ ). They were also inactive also against yeast reference strains (MIC $>1000 \mathrm{mg} / \mathrm{L}$ ). Notably, 1 was moderately active $(500>$ MIC $>125 \mathrm{mg} / \mathrm{L})$ against S. epidermidis bacteria. The moderate activity of 2 against $S$. aureus and S. epidermidis was further observed.

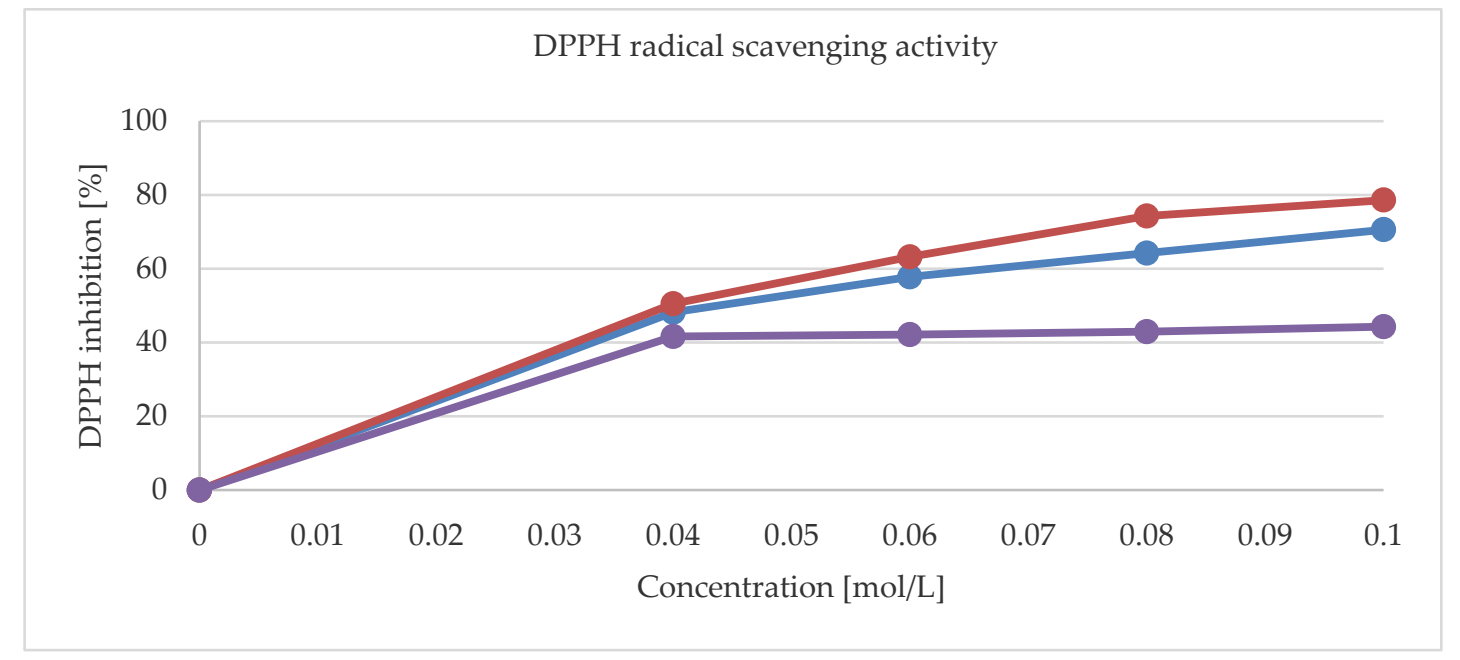

Figure 9. The (2,2- diphenyl-1-picrylhydrazyl) (DPPH) radical scavenging activity for $\mathbf{1}$ (red line), $\mathbf{2}$ (blue line), and pure thophylline (purple line).

\section{Conclusions}

In conclusion, we synthesized and thoroughly investigated two theophylline divalent $\mathrm{Cu}^{2+}$ and $\mathrm{Zn}^{2+}$ complexes 1 and 2, respectively. Their properties were compared to the already published by us $\mathrm{Mn}^{2+}, \mathrm{Co}^{2+}$, and $\mathrm{Ni}^{2+}$ compounds $3-5$. The $\mathbf{1}$ is characterized by distorted square pyramidal coordination with two theophylline ions and three water molecules within the $\mathrm{Cu}^{2+}$ coordination sphere. On the contrary, complexes 3-5 are isomorphic and they adopt octahedral geometry with coordinating water molecules positioned in equatorial positions and theophylline moieties placed axially. The theophylline ligands are coordinated to the central metal ion through the N7 atom of the imidazole ring. The crystal packing is affected by supramolecular puckered ribbons running along [010] axis as in $\mathbf{1}$ or [011] in 3-5. The fingerprint analysis revealed that despite differences in either coordinated or conserved waters topologies, structures $\mathbf{1}$ and 3-5 are driven by the nearly identical non-bonding contact settings. In 1 the two conserved waters 08 and 09 along with the coordinated water $\mathrm{O} 7$ form the unique double palindrome chain extending along the [100] crystal axis. Thermogravimetric analysis revealed that 1-5 decompose gradually along the pathways strongly affected by topology of water molecules in the crystal. Their radical scavenging ability is in the order 2 $>3,4>1>5$, notable higher than the pure theophylline itself. While all complexes are inactive against Gram-negative bacteria and they show moderate or mild activity against Gram-positive rods. On the contrary, the theophylline is inactive against either Gram-negative or Gram-positive species. The latter effect deserves further studies.

Author Contributions: Conceptualization, K.K., M.G. and W.M.W.; Methodology, A.P., I.K.-G., K.K. and M.G.; Validation, A.P., I.K.-G., K.K., M.G. and W.M.W.; Formal analysis, M.G. and W.M.W.; Investigation, A.P., I.K.-G., K.K., M.G. and W.M.W.; Writing-original draft preparation, M.G.; Writing—review and editing, K.K., M.G. and W.M.W.; Visualization, A.P. and M.G.; Supervision, K.K. and W.M.W. All authors have read and agreed to the published version of the manuscript.

Funding: This research received no external funding.

Conflicts of Interest: The authors declare no conflict of interest. 


\section{References}

1. Gilbert, R.M. Caffeine Consumption. Prog. Clin. Biol. Res. 1984, 158, 185-213. [PubMed]

2. Bujdosova, Z.; Gyoryova, K.; Ruzicka, A.; Melnik, M.; Koman, M. Crystal structures of two aromatiic zinc(II) caroboxylates: [Zn(4-chlorosalicylato $\left.)_{2}\left(\mathrm{H}_{2} \mathrm{O}\right)_{4}\right] \cdot 2$ theophylline $\cdot\left(\mathrm{H}_{2} \mathrm{O}\right)_{2}$ and unique [Zn(5-chlorosalicylato $)_{2}$ (isonicotinamine $\left.)_{2}\left(\mathrm{H}_{2} \mathrm{O}\right)\right]$. J. Chem. Crystallogr. 2011, 41, 1077-1084. [CrossRef]

3. Biradha, K.; Samai, S.; Maity, A.C.; Goswami, S. Supramolecular assembly of protonated xanthine alkaloids in their perchlorate salts. Cryst. Growth Des. 2009, 10, 937-942. [CrossRef]

4. Fredholm, B.B. Methylxanthines; Springer: Berlin/Heidelberg, Germany, 2011.

5. Petrucci, R.; Chiarotto, I.; Mattiello, L.; Passeri, D.; Rossi, R.; Zollo, G.; Feroci, M. Graphene Oxide: A smart (starting) material for natural methylxanthines adsorption and detection. Molecules 2019, 24, 4247. [CrossRef]

6. Monteiro, J.; Alves, M.G.; Oliveira, P.F.; Silva, B.M. Pharmacological potential of methylxanthines: Retrospective analysis and future expectations. Crit. Rev. Food Sci. Nutr. 2019, 59, 2597-2625. [CrossRef] [PubMed]

7. Petrucci, R.; Zollo, G.; Curulli, A.; Marrosu, G. A new insight into the oxidative mechanism of caffeine and related methylxanthines in aprotic medium: May caffeine be really considered as an antioxidant? Biochim. Biophys. Acta Gen. Subj. 2018, 1862, 1781-1789. [CrossRef]

8. Panusa, A.; Petrucci, R.; Lavecchia, R.; Zuorro, A. UHPLC-PDA-ESI-TOF/MS metabolic profiling and antioxidant capacity of arabica and robusta coffee silverskin: Antioxidants vs phytotoxins. Food Res. Int. 2017, 99, 155-165. [CrossRef]

9. Monteiro, J.P.; Alves, M.G.; Oliveira, P.F.; Silva, B.M. Structure-Bioactivity Relationships of Methylxanthines: Trying to Make Sense of All the Promises and the Drawbacks. Molecules 2016, 21, 974. [CrossRef]

10. Franco, R.; Oñatibia-Astibia, A.; Martínez-Pinilla, E. Health Benefits of Methylxanthines in Cacao and Chocolate. Nutrients 2013, 5, 4159-4173. [CrossRef]

11. Kossel, A. Über eine neue Base aus dem Pflanzenreich. Ber. Dtsch. Chem. Ges. 1888, 21, 2164-2167. [CrossRef]

12. Fischer, E.; Ach, L. Synthese des Caffeins. Ber. Dtsch. Chem. Ges. 1985, 28, 3135-3139. [CrossRef]

13. Sharron, H.F.; Konjeti, R.S.; Hengming, K.; Jackie, D.C. Inhibition of Cyclic Nucleotide Phosphodiesterases by Methylxanthines. In Methylxanthines, Handbook of Experimental Pharmacology; Fredholm, B.B., Ed.; Springer: Berlin/Heidelberg, Germany, 2011; pp. 93-134.

14. Santos, C.I.A.V.; Ramos, M.L.; Justino, L.L.G.; Burrows, H.D.; Valente, A.J.M.; Esteso, M.A.; Leaist, D.G.; Ribeiro, A.F.C. Effect of $\mathrm{pH}$ in the structure and mass transport by diffusion of theophylline. J. Chem. Thermodyn. 2017, 110, 162-170. [CrossRef]

15. Barnes, P.J. Pulmonary Perspectives. Theophylline. Am. J. Respir. Crit. Care Med. 2013, 188, $901-906$. [CrossRef] [PubMed]

16. Moratalla, R. Neurobiología de las metilxantinas. Trastor. Adict. 2008, 10, 201-207. [CrossRef]

17. Peck, C.C.; Nichols, A.I.; Baker, J.; Lenert, L.L.; Ezra, D. Clinical pharmacodynamics of theophylline. J. Allergy Clin. Immunol. 1985, 76, 292-297. [CrossRef]

18. Ashihara, H.; Crozier, A. Biosynthesis and metabolism of caffeine and related purine alkaloids in plants. In Advances in Botanical Research; Academic Press: Cambridge, MA, USA, 1999; Volume 30, pp. 117-205.

19. Nishijo, J.; Yonetani, I. The interaction of theophylline with benzylamine in aqueous solution. Chem. Pharm. Bull. 1982, 30, 4507-4511. [CrossRef]

20. Santos, C.I.A.V.; Ribeiro, A.C.F.; Esteso, M.A. Drug delivery systems: Study of inclusion complex formation between methylxanthines and cyclodextrins and their thermodynamic and transport properties. Biomolecules 2019, 9, 196. [CrossRef]

21. Budavari, S.; O’Neil, M.J.; Smith, A.; Heckelman, P.E. The Merck Index, 14th ed.; Merck: Rahway, NJ, USA, 2006.

22. Cavalieri, L.F.; Fox, J.J.; Stone, A.; Chang, N. On the nature of xantine and substituted xanthenes in solution. J. Am. Chem. Soc. 1954, 76, 1119-1122. [CrossRef]

23. Desoize, B. Metals and metal compounds in cancer treatment. Anticancer Res. 2004, 24, 1529-1544.

24. Shaw, C.F., III. Gold-based medicinal agents. Chem. Rev. 1999, 99, 2589-2600. [CrossRef]

25. Graf, N.; Lippard, S.J. Redox activation of metal-based prodrugs as a strategy for drug delivery. Adv. Drug Deliv. Rev. 2012, 64, 993-1004. [CrossRef] [PubMed] 
26. Van Rijt, S.H.; Sadler, P.J. Current applications and future potential for bioinorganic chemistry in the development of anticancer drugs. Drug Discov. Today 2009, 14, 1089-1097. [CrossRef] [PubMed]

27. Tang, X.; Liang, X. Metal-mediated targeting in the body. Chem. Biol. Drug Des. 2013, 81, 311-322. [CrossRef]

28. Gacki, M.; Kafarska, K.; Pietrzak, A.; Korona-Glowniak, I.; Wolf, W.M. Synthesis, characterization, crystal structure and biological activity of metal(II) complexes with theophylline. J. Saudi Chem. Soc. 2019, 23, 346-354. [CrossRef]

29. El Hamdani, H.; El Amane, M.; Duhayon, C. Crystal structure of tetraaquabis (1,3-dimethyl-2,6-dioxo-7Hpurin-7-ido-k N7)cobalt(II). Acta Crystallogr. Sect. E Crystallogr. Commun. 2017, 73, 1302-1304. [CrossRef]

30. Begum, N.S.; Monohar, H. Synthesis and X-ray crystal structure of a $\mathrm{Cu}^{\mathrm{II}}$-theophylline complex: $[\mathrm{Cu}($ theo) $\left.\left(\mathrm{H}_{2} \mathrm{O}\right)\right] \cdot 2 \mathrm{H}_{2} \mathrm{O}$. Polyhedron 1994, 13, 307-312. [CrossRef]

31. Wang, H.; Hu, T.; Wen, R.; Wang, Q.; Bu, X. In vitro controlled release of theophylline from metal-drug complexes. J. Mater. Chem. B 2013, 1, 3879-3882. [CrossRef]

32. Hao, X.M.; Zhao, S.; Wang, H.; Wu, Y.B.; Yang, D.; Zhang, X.F.; Xu, Z.L. In vitro release of theophylline and cytotoxicity of two new metal-drug complexes. Polyhedron 2018, 142, 38-42. [CrossRef]

33. Forizs, E.; Debreczeni, A.; Patrut, A. Synthesis, structure and DFT calculations on complexes of palladium (II) with theophylline. Rev. Roum. 2010, 55, 697-704.

34. Caldwell, K.; Deacon, G.B.; Gatehouse, B.M.; Lee, S.C.; Canty, A.J. Organomercury medicinal chemistry. Synthesis and structure of a ( $\beta$-methoxyethyl)mercury(II) derivative of $\mathrm{N}(7)$-deprotonated theophylline, $\left[\mathrm{Hg}\left(\mathrm{C}_{3} \mathrm{H}_{7} \mathrm{O}\right)\left(\mathrm{C}_{7} \mathrm{H}_{7} \mathrm{~N}_{4} \mathrm{O}_{2}\right)\right]$. Acta Cryst. C 1984, 40, 1533-1536. [CrossRef]

35. Aoki, K.; Yamazaki, H. Interaction of tetrakis(- $\mu$-carboxylato)dirhodiurn(II), an antitumour agent, with nucleic acid bases. X-ray crystal structures of $\left[\mathrm{Rh}_{2} \text { (acetato }\right)_{4}$ (theophylline $\left.)_{2}\right]$ and $\left[\mathrm{Rh}_{2}(\text { acetato })_{4}(\text { caffeine })_{2}\right]$. J. Chem. Soc. Chem. Commun. 1980, 926, 186-188. [CrossRef]

36. Griffith, E.H.; Amma, E.L. Reaction of $\mathrm{PtCl}_{4}{ }^{2-}$ with theophylline: X-ray crystal structures of bis(theophyllinum) tetrachloroplatine(II) and theophyllinum trichlorotheophyllineplatinate(II). Inorg. Chem. $1979,7,322-324$.

37. Feng, J.; Du, X.; Liu, H.; Sui, X.; Zhang, C.; Tang, Y.; Zhang, J. Manganeseese-mefenamic acid complexes exhibit high lipoxygenase inhibitory activity. Dalton Trans. 2014, 43, 10930-10939. [CrossRef] [PubMed]

38. Rigaku Oxford Diffraction; CrysAlisPro 1.171.39.33c; Agilent Technologies UK Ltd.: Yarnton, UK, 2017.

39. Sheldrick, G.M. SHELXT-Integrated space-group and crystal-structure determination. Acta Crystallogr. Sect. C Struct. Chem. 2015, 71, 3-8. [CrossRef]

40. Dolomanov, O.V.; Bourhis, L.J.; Gildea, R.J.; Howard, J.A.K.; Puschmann, H. OLEX2: A complete structure solution, refinement and analysis program. J. Appl. Cryst. 2009, 42, 339-341. [CrossRef]

41. HüBschle, C.B.; Sheldrick, G.M.; Dittrich, B. ShelXle: A Qt graphical user interface for SHELXL. J. Appl. Cryst. 2011, 44, 1281-1284. [CrossRef]

42. Macrae, C.F.; Bruno, I.J.; Chisholm, J.A.; Edgington, P.R.; Mccabe, P.; Pidcock, E.; Rodriguez-Monge, L.; Taylor, R.; Van De Streek, J.; Wood, P.A. Mercury: Visualization and analysis of crystal structures. J. Appl. Cryst. 2008, 41, 466-470. [CrossRef]

43. Spek, A.L. Structure validation in chemical crystallography. Acta Crystallogr. Sect. D Biol. Crystallogr. 2009, 65, 148-155. [CrossRef]

44. McKinnon, J.J.; Jayatilaka, D.; Spackman, M.A. Towards quantitative analysis of intermolecular interactions with Hirshfeld surfaces. Chem. Commun. 2007, 37, 3814-3816. [CrossRef]

45. Żesławska, E.; Korona-Głowniak, I.; Szczesio, M.; Olczak, A.; Żylewska, A.; Tejchman, W.; Malm, A. Structural analysis and antimicrobial activity of $2[1 \mathrm{H}]$-pyrimidinethione/selenone derivatives. J. Mol. Struct. 2017, 1142, 261-266. [CrossRef]

46. Bernstein, J.; Davis, R.; Shimoni, L.; Chang, N. Patterns in hydrogen bonding: Functionality and graph set analysis in crystals. Angew. Chem. Int. Ed. 1995, 34, 1555-1573. [CrossRef]

(C) 2020 by the authors. Licensee MDPI, Basel, Switzerland. This article is an open access article distributed under the terms and conditions of the Creative Commons Attribution (CC BY) license (http://creativecommons.org/licenses/by/4.0/). 